\title{
DEAF ADULTS AS ROLE MODELS FOR THE HEARING WORLD: A LITERATURE REVIEW
}

\author{
Stergiani Giaouri ${ }^{1 i}$, \\ Spyridoula Karipi ${ }^{2}$, \\ Anastasia Alevriadou ${ }^{3}$, \\ Marianna Hatzopoulou, ${ }^{4}$, \\ Vassilis Kourbetis ${ }^{5}$ \\ ${ }^{1}$ Department of Primary Education, \\ University of Western Macedonia, \\ Florina, Greece \\ ${ }^{2}$ Head of the Kindergarten \\ for the Deaf and Hard of Hearing of Argyroupolis (KDA), \\ Athens, Greece \\ ${ }^{3}$ Department of Psychology, \\ Aristotle University of Thessaloniki, \\ Thessaloniki, Greece \\ ${ }^{4}$ Head of the Local Assessment and Support Centre, \\ 2nd B Athens, Greece \\ ${ }^{5}$ Counsellor A of Special Education, \\ Independent Scientific Counselors Office, \\ Ministry of Education \& Religious Affairs,
}

Greece

\begin{abstract}
:
Although deaf role model projects have existed for some time and their benefits and outcomes for deaf children/young people and their parents have been recorded, almost no attention has been paid to the experiences of the deaf people who take on these roles. Additionally, the experiences of being a deaf role model have been little explored in the literature. This paper explores available literature on role models for supporting families of deaf children and hearing practitioners. Most deaf people (about 95\%), all over the world, have hearing parents and do not meet deaf adults and sign language before the age that formal primary education starts. The majority of hearing parents do not come in touch with deafness even after their child is diagnosed of being deaf. But it's really crucial for families to have resources that allow them to help their child develop language and have full interaction with their family. Additionally, deaf role models can play a vital role in the development of deaf children's knowledge, skills, and perceptions. Further work would be also required to understand the longer-term benefits and further developments that deaf role models may wish to initiate.
\end{abstract}

'Correspondence: email sgiaouri@uowm.gr 
Keywords: deaf role models, deaf children, families, professionals

\section{Introduction}

There are 34 million children with disabling hearing loss, which is defined as greater than $30 \mathrm{~dB}$ hearing loss in children (World Health Organization, 2018). If hearing loss is not addressed early, consequences include the possibility of delayed language development, academic underachievement, social isolation, higher risk of injuries, and increased poverty (WHO, 2018). Furthermore, with 90\% of deaf babies residing in low-resourced countries where quality health care and educational opportunities can be challenging, it is important to identify effective ways to address and improve the quality of life for deaf children (Gale et al., 2021; Storbeck \& Young, 2015).

The overwhelming majority of deaf children (90-95\%) are born to hearing parents (Hadjikakou \& Nikolaraizi, 2008; Mitchell \& Karchmer, 2004; Moores, 2001; Schein \& Delk, 1974), most of whom are likely to have had little or no experience with the norms, values or language of the deaf community (Hindley, 2005; Young, 2003), or lack of information that will help them open up their deaf child's world visually and make language available to their child. This lack of knowledge and contact marginalizes deaf people, their sign language, and their deaf culture (Hoffmeister \& Caldwell-Harris, 2014). Many European countries acknowledge the fact that hearing people do not know sign language at all, and they rarely socialize with deaf adults as well. This lack of communicative competence is identified as the root of all problems arising in the family and growing with practitioners, co-workers, and the hearing world in general. Furthermore, hearing people also have misconceptions about deaf people, sign language, and the deaf community (Moores, 2001; Woodward, 1972).

Most hearing people do not meet deaf people unless they have deaf members in the family, at school or as adults in the workplace and the community. When children are recognized as being deaf, their parents' opportunities to meet deaf people are often limited, as professionals who work with deaf children and their families are often hearing. Families of deaf children come into contact mainly with doctors and speech therapists, after the diagnosis of deafness hence there is a "pathological" approach of the problem and non-acceptance of sign language and deafness. In general, the family or coworkers of deaf people don't know and don't use sign language in their everyday communication. Although professionals who work with deaf children and their families will bring in their own values and expertise, give information, and offer advice, they will not be able to relate first-hand experiences or give an insight into what it is like to be a deaf person and what a deaf person can achieve. These benefits are being slowly recognized by professional support services (Humphries, Kushalnagar, Mathur, Napoli, Padden, \& Smith, 2017; Rogers \& Young, 2011).

According to Jackson and Turnbull (2004), further research is needed to examine the effects of different supports and service delivery models on indicators and domains of family quality of life. Several studies in the literature (Holcomb, 2013; Young, 2003) have suggested the benefits of supports, including social support, parenting models, and 
access to information and training. In the available literature, no sufficient data exists to indicate supports that are most beneficial in reducing the perceived stress of decision making and problem solving, reducing time demands, enhancing mutually accessible communication, and facilitating access to services and the community. More research is needed to determine the best match between different supports and methods of delivery (such as direct instruction, coaching, individual counseling, and parent-group meetings) and different child and family characteristics. Additional research is also needed to consider the impact of different service delivery models as they are related to deafness and family life (primary provider model, activity-based instruction, and home-based vs center-based services).

Neverthelesss, because of the absence of any previous experiences with hearing loss, hearing parents experience a lot of challenges with the upbringing of their children, especially as regards their language and their social and emotional development (Hadjikakou \& Nikolaraizi, 2008; Hindley, 2005). Many hearing parents fear that while they can make informed decisions regarding their deaf child's education and/or language choices, they feel at a loss when it comes to the intangibles, or what it is like to live with deafness. Communication difficulties are also among the major challenges they encounter (Marschark et al., 1997; Ogden, 1997; Siegel, 2000).

The current research suggests that hearing parents are more likely to use spoken language as the primary mode of communication with their deaf children (Gravel \& Galatioto, 2003; Haualand \& Holmström, 2019) and to socialise with hearing people (BatChava, 2000; Maxwell-McCaw, 2001). Several researchers have reported that deaf children with hearing parents communicate in a manner not conducive to their optimal cognitive, psychological, or social development (Hadadian \& Rose, 1991; Hadjikakou \& Nikolaraizi, 2008; Spencer \& Gutfreund, 1990). In some other studies, where hearing parents were signing with their children, positive results regarding family interaction and acceptance, deriving from the use of sign language by their hearing parents, were highlighted. More specifically, the participants in the study by Haualand and his colleagues (2003), stressed the importance of their hearing parents learning sign language when the participants were young to ensure their acceptance by the family, to achieve effective communication at home, as well as to prevent personal frustrations and intrafamilial conflicts.

Moreover, it has been reported that there is a high correlation between communicative competence in sign language and quality of interaction between deaf and hearing people (Haualand \& Holmström, 2019; Kourbetis, Adamopoulou, \& Ferentinos, 2005). It has been also argued in the literature for decades now that healthy, realistic expectations for the deaf, positive reactions to deafness, and exposure to deaf identity, form healthy relationships with deaf and hearing people alike.

Due to the importance of early and accessible language and communication and the development of positive self-esteem, it is critical that parents have resources that allow them to help their child develop language and have full interaction with their family. Having deaf adults connect with families and collaborate with professionals is important (Hatzopoulou, 2008; Mitchell \& Karchmer, 2004; Sass-Lehrer, 2016). The early 
years greatly impact deaf children's long-term achievement and well-being, and early exposure to fluent linguistic and positive cultural role models are critical in early childhood settings, as well as in early intervention services for families. Hearing adults having or working with deaf people of all ages will benefit from contact with deaf adults in terms of understanding and accepting deafness and deaf culture (Holcomb, 1997; Lane, Hoffmeister, \& Bahan, 1996; Mahshie, 1995; Moores 1996). Moreover, deaf adults can provide a unique perspective from their own experiences as well as providing culturally created solutions for effective living (Holcomb, 2013).

When children lack role models with whom they can identify themselves, they are statistically more likely to have low self-esteem, to have limited social and vocational options, and are even more likely to drop out of high school (Hintermair, 2008; McKee \& Rosen, 2014; Napier, Leigh, \& Nann, 2007). It is crucial for parents and educators to recognize the importance of identifying role models who can exemplify living life with a hearing loss. Deaf children benefit from seeing how deaf adults navigate the day-to-day in their world - for example, how they request a captioning device at a movie theatre; what strategies they use to navigate a bank; how they handle rude stares or questions from well-meaning people at the grocery store. Because students subconsciously develop schemas for their daily lives based on what they see the adults in their lives do, it is ideal that deaf children have access to deaf adults on an informal basis. Acquiring a bicultural identity is crucial for most deaf people in developing a productive and rewarding life.

\section{Defining Role Models}

The literature relating to role models draws from a variety of theoretical frameworks, orientations, and research methodologies (see, e.g., Allen, Eby, Poteet, Lentz, \& Lima, 2004; Eby, Allen, Evans, Ng, \& Dubois, 2008; Zand et al., 2009). There are many definitions of role models in the research literature, both in terms of role models' personal characteristics and the function of a role model relationship. These definitions vary from broad, such as informal life coaching, to programmatic, such as the Big Brothers/Big Sisters program (Thompson \& Kelly-Vance, 2001). Some scholars define the mentoring relationship as one in which the role model provides personal support to an individual who needs a relational infrastructure and guidance (Rhodes, 2005). Domains in which role models provide support and guidance also vary, and can include academic, workplace, and community settings (Eby et al., 2008). Programs and structures for role models vary depending on whether the intention is to enhance specific skills, such as literacy (da Costa, Klak, \& Schinke, 2000), or to prevent problem behaviors such as truancy, drug use, or other criminal activity (see, e.g., the Check and Connect Student Engagement Intervention Model by Sinclair, Christenson, \& Thurlow, 2005).

Additionally, for deaf children, a deaf role model may serve as a mentor for both the child and the child's family. Specifically, Cawthon et al. (2016) identified several themes related to role models for older deaf children, and the review highlighted key themes and recommendations applicable to educational settings for younger deaf children. The themes were: (a) role models address a critical need in the development of 
the deaf child, (b) they contribute to important developmental processes for the deaf child, (c) certain elements have been distinguished as effective in role modeling for the deaf child, and (d) there is a need for multidimensional cultural affiliations (e.g., race, ethnicity, gender, sexual orientation) in order to impact the development of the deaf child.

In particular, the literature on role models who work with diverse populations emphasizes both social and academic benefits for minority youth (Bone \& Slate, 2011; Haycock, 2001). For example, it was found that in school contexts, minority students performed better academically if they were taught by minority teachers (Meier \& Stewart, 1992). Possible explanations include reduced negativity around discipline issues, increased student comfort levels in the classroom, and the perception on the part of students that the minority teachers were strong role models (Tyler, Yzquierdo, LopezReyna, \& Flippin, 2004). Therefore, there may be an opportunity for role models to have a protective influence on deaf individuals as they navigate barriers to full access at school and in the workplace.

\section{The role-modelling process: Experiences and perspectives}

In a variety of contexts, deaf individuals often must navigate multiple educational, social, psychological, and physical barriers. It is frequently proposed that role models meet an important need for successful navigation in such contexts. The role-modeling process includes multiple elements, and individuals' relationships with their role models vary widely. Role-modeling processes may include supporting, guiding, or mentoring the individual as a friend (Thompson \& Kelly-Vance, 2001), teaching or coaching the individual through important life transitions, or providing empathy (Cawthon et al., 2016; Foster \& MacLeod, 2004).

Deaf adults can be excellent role models for deaf children and their families. By drawing on their own experiences, they can show families that deafness does not need to be a barrier to achievement. The prospect of meeting and getting to know deaf adults who have experience of growing up deaf and having opportunities to ask questions about what it is like to be deaf could challenge the negative stereotypes about deaf people (Sutherland et al., 2003); in other words, 'seeing is believing'. Moreover, deaf role models can ease parents' fears and share positive life experiences; inform families of upcoming deaf events; provide access to a support network; give 'real life' examples about selfadvocacy; and to provide authentic opportunity to practice sign language (Byatt, Dally, \& Duncan, 2019; De Clerck \& Golos, 2019; Rogers \& Young, 2011).

The deaf role models work with deaf children and young people - helping them improve their communication skills, self-confidence, aspirations, self-advocacy skills and positive deaf identity. They are expected to share their personal experiences as a deaf young person and serve as positive role models for the deaf children and young people they work with. Meeting deaf adults will not only benefit families of deaf children, but also is important in other contexts such as education. Leeson $(2006$, p. 14) emphasized the importance of deaf adults' input into education; thus, "... the stigmatization of signed 
languages in education for the Deaf in many countries ignores the experiences of Deaf adults whose experiences must help shape future policy".

There is evidence that deaf children of families who received services from deaf mentors focusing on bilingual-bicultural programming made more language gains than the deaf peers without deaf mentors (Watkins, Pittman, \& Walden, 1998). Additionally, parents who had encounters with deaf adults felt a "strong sense of competence in regard to their child's upbringing" (Hintermair, 2000, p. 41), felt that their sign language skills, as well as the communication interactions with their deaf or hard-of-hearing children, improved (Delk \& Weidekamp, 2001), they also felt it was important to connect with deaf adults (Jackson, 2011), and that their child might have an improved quality of life (Gale et al., 2019; Petersen, Kinoglu, Gozali-Lee, \& Martin Rogers, 2016). Furthermore, the deaf adults, who were role models for young deaf children and their families, felt the families they worked with had "more positive perspectives on deafness and positive outlooks for their children" (Rogers \& Young, 2011, p. 15).

In addition to connecting families with deaf adults, it is also important that deaf and hearing professionals collaborate throughout the system for practical and ethical reasons. From a practical perspective, deaf adults are experts in issues important to deaf people and can adequately describe what it means to be deaf. From an ethical perspective, infusing deaf adults in the system or with a family reduces misrepresentations or misconceptions (Benedict \& Sass-Lehrer, 2007). Furthermore, having a diverse representation of highly qualified professionals who happen to be deaf infused throughout the early intervention system in leadership roles is important for parents to see that deaf professionals have diverse expertise and professions (Gale et al., 2021; Yoshinaga-Itano, 2014).

Infusing deaf adults in the early intervention system is a way for deaf adults to be ingrained in the system at all levels providing parents support regarding the health and education systems assuming diverse roles throughout the system, including educational, leadership, and medical positions. It is important to infuse deaf adults in early intervention because hearing parents of deaf children may have little or no experience with deaf people or even expectations regarding their deaf child (Mitchell \& Karchmer, 2004).

Programs that have diverse representation of highly qualified deaf professionals in first-contact roles simply provide parents with the most qualified professionals who may happen to be deaf, too. When parents interact with deaf adults, it is not because they are deaf or hard of hearing, but because they have a significant service and expertise to provide the family (Gallegos \& Lawrence, 2010; Yoshinaga-Itano, 2014).

Furthermore, deaf adults working as deaf role models or mentors with families and deaf young people is a growing trend particularly in educational settings. Wilkens and Hehir (2008) also recommend that deaf students should have access to deaf adults who might be seen as role models to them, to build deaf students' social capital, as this could serve to expand their social network knowledge and reduce the risk of isolation. Deaf adults are sometimes employed in educational settings with deaf children, where strong emphasis is placed on the importance of deaf native sign language users' 
involvement in sign bilingual approaches to deaf education, as sign language tutors and teachers (Ahlgren \& Hyltenstam, 1994; Davies, 1991; Svartholm, 1993). However, these researchers were mainly concerned with sign bilingual education approaches, rather than deaf role models as a family-based intervention approach.

Hence, there are many reasons for introducing deaf adults to parents of deaf children, such as to educate hearing parents about how to communicate with their deaf children (Mohay et al. 1998; Takala et al., 2001); to promote bilingual-bicultural environments for deaf children (Watkins et al., 1998); to enhance parents' knowledge and access to information (Young et al., 2000); to promote deaf children's language development including literacy skills (Drasgow, 1993; Schimmel \& Monaghan, 1983); and to connect them to the deaf community (Hulsebosch \& Myers, 2002). Research focusing on parents' experiences of meeting deaf adults via intervention programs is not new (Takala et al., 2001). From parents' reports, it was found that meeting deaf adults resulted in several benefits: positive attitudes towards deaf people and deaf culture (Mohay et al. 1998), feeling more able to parent their deaf children by reducing their feelings of isolation (Hintermair, 2000), learning more sign language (Takala et al., 2001), and making improvements to their deaf children's communication competence (Takala et al., 2001; Watkins et al., 1998).

There has also been some research involving deaf people's perspectives on deaf role models for deaf people, such as the work undertaken by Parasnis and Fischer (2005) and De Clerck (2007). Parasnis and Fischer (2005) advocated the importance of visible role models for minority ethnic deaf students, noting also the negative assumptions held by the hearing population. They interviewed some of the academic members of staff from ethnic minorities at a college for deaf people, some of whom were deaf themselves, about their views on the importance of role models for minority ethnic deaf people. Although it was reported that none of those participants saw themselves as role models exclusively for minority ethnic students, it was stated that they were aware that some students saw them as role models and had contacted them for advice (Parasnis, Samar, \& Fischer, 2005). It was noted, however, that this input was surplus to their job descriptions and that some of them felt overwhelmed by this additional responsibility. In two other studies in Flanders (De Clerck, 2007) and the UK (Young et al., 2000), the incidental nature of being a deaf role model was also evidenced among deaf people who were professionals in their own chosen fields and/or deaf community leaders. In effect, role model status may be something perceived and attributed, rather than deliberately sought out or created through a job description (Rogers \& Young, 2011).

Despite these studies, little is known about the perspectives of deaf adults who have acted as deaf role models for parents of deaf children, in relation to their experiences of being involved in deaf role model projects, or their perceptions of how this role has impacted them personally. 


\section{Impact of Deaf Role Models}

Researchers have identified multiple ways role models can have an impact on the lives of deaf children and their families. First, they can positively affect parental attitudes, which can then shape the deaf child's attitudes (e.g., Rogers and Young 2011). Second, a role model's fluent sign language skills and affiliation with the deaf community can encourage the deaf child's language and identity development (Cawthon et al. 2016). Having deaf role models affiliated with the deaf community also helps build their selfesteem and pride about being deaf (e.g., Nikolaraizi \& Hadjikakou 2006).

Cawthon et al. (2016) also argued that deaf role models are most effective when they have both high expectations for and effective communication with the deaf child (e.g., share a similar accessible communication mode such as sign language). All of these build up a child's resilience against psychopathological perspectives, and resilient deaf children have an easier time navigating through a hearing world (Hauser 2011). This facilitates a greater sense of self and confidence about that child's future success (Foster and MacLeod 2004).

These themes reinforce also the importance of knowledgeable cultural and linguistic models in early childhood settings. The early years greatly impact deaf children's long-term achievement and well-being, and early exposure to fluent linguistic and positive cultural role models are critical in early childhood settings. Golos et al. (2018) in their research examined the presence and use of cultural and linguistic role models in early childhood environments, instruction, and interactions to see whether they aligned with a cultural or psychopathological perspective of deafness. Their results indicated that classrooms varied in the type and frequency of cultural and linguistic offerings and that depended, at times, on the primary mode of communication used in the classroom, the teachers' hearing level, and their sign language skill level. Even though recent research indicates that alternative avenues for providing role models (e.g., electronic and print media, adults coming into the classroom) are promising, they are not being utilized to their full potential (Moses, Golos, \& Holcomb, 2018).

Moreover, according to Gale et al. (2021), results of their study showed deaf adults serve as role models and language providers, and typically provide educational and information support. However, results also showed it is not common for deaf adults to be in roles as a first point of contact. Once a child is identified, a health professional, and/or a director is the first contact for the family. Additionally, in this research, respondents reported that families do not have a diverse range of deaf professionals to connect with in early intervention programs. This article concludes with a call to action for infusing deaf adults in early intervention programs that include formalisation, collaboration, education, and infusion.

A deaf role model may serve another purpose: this person can be deaf and represent a racial or ethnic background or sexual orientation similar to the deaf child. Survey data highlighted earlier suggest (Gallegos \& Lawrence, 2010) that few deaf children interact with adults who share such backgrounds. Through the same means mentioned earlier (e.g, interacting with deaf role models), children can witness the 
capabilities of deaf people from diverse backgrounds succeeding in relationships, education, work, and beyond. This may be even more important for some deaf children than the adult simply being deaf (Parasnis, Samar, \& Fisher, 2005). Thus, role models can be an influential component of a child's development and learning.

Specifically, in the study carried out by Rogers and Young (2011), it was shown the importance of having a wide diversity of deaf role models was not only potentially beneficial for participating children and families, but also for the deaf role models themselves. Having the opportunity to meet other deaf people with differing life experiences, backgrounds, communication preferences, and skills not only led to the widening of their personal experiences, but also allowed them to access broader perspectives, other than their own, of being a deaf person and of deafness in general.

Furthermore, Rogers and Young (2011) on their study have highlighted the positive impact the training had on the deaf role model, including the development of new skills that were seen to be transferable to other situations. Additionally, the ongoing support given to the deaf role models was seen to be vital to the success of the project. Such attention to continual structures and processes of support, rather than simply initial training, has been identified as lacking in other studies (Parasnis \& Fischer, 2005; Sutherland et al. 2003). This also applies to deaf professionals who work with deaf children and their families and/or professionals working with them; for example, Parasnis and Fischer (2005) noted the lack of support for the staff members from minority groups and felt that something should have been in place to help them not to feel overburdened and underappreciated.

\section{Benefits of Role Models}

Gale et al. (2021) suggest that when deaf adults connect with young deaf children regularly, cognitive development is positively impacted in addition to language and social-emotional development. By extension, the strategies that deaf adults are using with their children can be shared with and taught to all parents in order to support their own child's development.

Outcomes of mentoring relationships are often defined in terms of the benefits gained by the mentee as well as potential amelioration of negative behaviors and outcomes. Evaluations of role b model effectiveness are sometimes targeted toward an intended goal, such as achievement in school for children classified as 'at-risk youth' or progress up a career ladder (Cawthon et al., 2016; Kram, 1985; Thompson \& Kelly-Vance, 2001). Thompson and Kelly-Vance (2001) describe a further example from a specific mentoring program: Boys who had mentors from the Big Brothers/Big Sisters program (who had not previously experienced academic success) had significantly higher scores in areas of reading and math than boys who did not have mentors. A meta-analysis of general mentoring outcomes for mentees in hearing populations that investigated the broader impact of mentoring on attitudes, achievement, and motivation to continue in work and educational pursuits demonstrated a significant, but small, overall effect size of mentoring (Eby et al., 2008). 
The effect of mentoring appears to vary in strength across settings, with larger effects found in workplace and academic settings (Eby et al., 2008). Zand et al. (2009) looked more deeply into these constructs, investigating how the quality of the mentorship relationship, defined as alliance, affected the strength of mentees' relationships with adults, family bonding (e.g., attachment and degree of supervision), school bonding (e.g., degree to which school was valued), and life skills (e.g., standing up to peer pressure, self-efficacy). Zand et al. (2009) found that the quality of the mentorship relationship had a positive impact on these measured outcomes after 8 months of the relationship. Although not explicitly defined as social capital, successfully building, and maintaining relationships is a critical skill in gaining access to those essential networks. These (and similar) meta-analyses of mentorship outcomes in the general population provide a reference point for further analysis of these outcomes specifically for deaf individuals.

As Cawthon et al. (2016) state, role models appear to contribute to a multitude of developmental processes (for example, shifting parental attitudes, language development, identity development and psychosocial development) not only for deaf individuals but also for their families.

\subsection{Parental Attitudes}

The literature has suggested that several factors may influence the degree and type of impact of deafness on family life, including the severity of hearing loss, a family's ethnicity, the hearing status of parents, the education of parents, the mode of communication used, the proficiency of partners in child's communication mode, and family's access to social supports and parenting models. Additional research on assessing and measuring family quality of life is warranted to identify tools that are sensitive to the unique experiences of families who include members that are deaf. Measurement tools are needed to examine the effects of deafness on the overall family well-being (Jackson \& Turnbull, 2004).

Furthermore, recommendations to have deaf adults connect with families to provide support and to collaborate with professionals throughout the system have been published as best practice principles in the International Consensus Statement (Moeller et al., 2013). The first explicit best practice focuses on social and emotional support systems for families and recommends that service providers "support connections between families and adult role models who are Deaf or hard of hearing" (Moeller et al., 2013, p. 435). The intention of this principle is to connect families to "support systems so they can accrue the necessary knowledge and experiences that can enable them to function effectively on behalf of their children" (Moeller et al., 2013, p. 435). Supporting evidence includes "parents who have many contacts with hearing-impaired adults show evidence of a strong sense of competence in regard to their child's upbringing" (Hintermair, 2000, p. 41). Also, in a study examining supports and resources for families with deaf children, parents rated connecting with mentors and role models as important (Gale et al., 2021; Jackson, 2011).

The second explicit recommendation focuses on collaborative teamwork and recommends that early intervention teams include "individuals who are Deaf or hard of 
hearing (role models/mentors)" (Moeller et al., 2013, p. 440). The intention of this principle is to establish an optimal team through transdisciplinary teamwork focusing on the family that "includes professionals with experience in promoting early development of children who are Deaf or hard of hearing" (Moeller et al., 2013, p. 440). Supporting evidence includes the parents' needs to have deaf role models to better understand the capabilities of their deaf children (Rogers \& Young, 2011), and includes promoting language development (Gale et al., 2021; Watkins et al., 1998).

The overall findings indicated that parents who had access to mentors or role models demonstrated a positive shift in attitudes, moving toward a more optimistic perspective on their deaf child's potential (Byatt, Dally, \& Duncan, 2019; Cawthon et al., 2016; De Clerck \& Golos, 2019; Kecman, 2018; Rogers \& Young, 2011; Watkins, Pittman, $\&$ Walden, 1998). It appears that having a Deaf mentor or role model may confer those benefits (see, e.g., Henderson, Johnson, \& Moodie, 2014). One study explored differential outcomes that resulted from families working with deaf mentors as opposed to non-deaf mentors. The study demonstrated that parents who had a deaf mentor provided better accessible-language models (both signed and spoken) during home observations and expressed a desire for their children to read and write well, to learn sign language, and to have deaf friends (Watkins et al., 1998). The parents who were not matched with deaf mentors were more focused on academic and career success. Overall, parents who had a deaf role model working with their family demonstrated a positive shift in attitudes about their child's future (Rodgers \& Young, 2011; Watkins et al., 1998).

In addition, parents who worked with deaf mentors reached an understanding that developing a deaf identity was an important contributor to their child's overall wellbeing (Selwood, 2005). Yet it is necessary to acknowledge that conflict may occur between families and their mentors, role models, or the surrounding deaf community, which may result in parents feeling that they are being ostracized (Luckner \& Velaski, 2004). This conflict often surrounds challenging decisions about communication choices, assistive listening technologies, and educational options, which are a perpetual presence on the deaf education landscape. These conflicts can also reduce the positive benefits of a role model regarding how families are able to tap into social capital resources for their deaf children. However, the child may grow as a part of this experience and see different possible alternatives that were not a part of the family dialogue prior to the introduction of an alternative perspective from the deaf community.

\subsection{Language Development}

In synthesizing the literature, we identified language development as an important and freestanding developmental process that role models might be able to support for deaf youth. The communication and language contexts of a deaf child's development also require that particular attention be paid to this issue. Yet only one study was found that explicitly made the link between mentoring activities and subsequent language development (Watkins et al., 1998). As mentioned previously, the parents who worked with deaf mentors provided more accessible language models (both signed and spoken) for their deaf children. However, their children also demonstrated greater language gains 
in expressive and receptive levels of both languages that were used (both signed and spoken), a finding that indicates that a deaf role model or mentor can make a direct contribution to deaf young children's language development, albeit within a constrained time frame, that of early childhood. Whether role models can support the language development of deaf individuals during later developmental periods remains to be explored (Scott \& Henner, 2020).

\subsection{Culture and Identity Development}

Culture is defined by Parasnis (1996) as a way of life. Culture is an integrated pattern of human knowledge, beliefs, and behavior that is acquired as a member of society. It includes the ideas, assumptions, and values of a group, and shapes all that we do. There are two different ways to view deafness: deafness as a disability and a medical pathology, or deafness as a culture with its own values, traditions and customs (Wald \& Knutson, 2000). Deaf culture is passed on through social interactions and language in the deaf community. Being a member of the deaf culture is contingent on many factors such as knowledge of the language, hearing status of family members, cultural competence, and personal identification. Being born deaf or hard of hearing does not automatically mean that one is a member of deaf culture. Indeed, Wald and Knutson (2000) say that deaf cultural identity is not based entirely on hearing status and instead it is defined as a combination of self-perceptions and the associated feelings an individual possesses about him/herself in regard to a cultural group.

Identity is how individuals perceive themselves and how the individual is defined by others. Thus, while a personal choice, identity is shaped by outside influences as well. Identity formation continues throughout the life span. Progression of an individual's selfidentity as a person who is deaf or hard of hearing is a long process of self-discovery and often there is no diffusion of deaf culture from parents to children unless an individual is born into a deaf family. Because most children who are born deaf or hard of hearing are born to hearing parents, they often learn knowledge of deaf culture and its values and beliefs from their peers who are also deaf or hard of hearing. Parasnis (1996) describes this as a lateral transmission of culture since it is from peer to peer, rather than vertical, parent to child. The identity of deaf or hard of hearing individuals develops based on the extent to which being deaf or hard of hearing is most important in daily life. A person's deaf identity depends on parental hearing status and often how parents describe their children (Leigh, 2009).

If the environment and interactions play a substantial role in identity development, then deaf children need significant time and experiences with adults like themselves who are successful (e.g., Cawthon et al. 2016). Role models appear to make an important contribution to identity development for deaf adolescents, providing opportunities to develop, evolve, and 'test out' one's identity. Social networks are a key mechanism by which individuals develop their identity. Hintermair (2008) describes a theoretical shift in the field to the concept of 'identity work', in which individuals seek to bring together different components of their lives into a meaningful, purposeful whole (Chandler \& Roberts-Young, 1998). Identities thus adapt and respond to one's daily 
interactions, a socially constructed process that results in different understandings of self and agency in different experiences and settings (Baumeister, 1997). Because many of the role models for deaf individuals come from the deaf community, it is a key resource for both formal and informal role model relationships for deaf youth.

Acculturation into a community is an important part of how role models shape and support an individual's own identity development (Hintermair, 2007, 2008). Like other ethnic groups, the deaf community has its own language, culture, and societal norms. A deaf role model who is strongly affiliated with the deaf community appears to be a strong facilitator of social capital, creating linkages between the deaf youth and other individuals in the community and expanding the support group available to that individual. A role model who understands that there are multiple ways of viewing what it means to be deaf-that there are negative views but also positive sociocultural models of deaf identity, can help raise self-esteem and pride in being a part of such a strong and diverse community. The development of deaf cultural identity can build self-esteem; it has to do with knowing oneself and where one comes from, and represents 'ownership and pride' (Covell, 2006).

Educational contexts in which there are higher numbers of deaf individuals from whom potential role models may be drawn also appear to be highly salient contexts for the exploration of deaf identity (Nikolaraizi \& Hadjikakou, 2006). Schools can offer a connection to a world beyond one's family, particularly for those deaf youth who do not have access to the deaf community. The school thus serves as a point of connection for potential role models for deaf youth. Deaf adults' educational experiences clearly play a significant formative role in their identity development, which may be highly dependent on whether they attended schools for the deaf or had access to deaf role models outside of school (Nikolaraizi \& Hadjikakou, 2006).

However, because deaf youth may not have effortless access to a pool of diverse role models in their immediate community, formalized structures for the provision of role models can enable necessary representations of possible selves that are attainable and relate to the young person's own experience (McKee \& Connew, 2001; Selwood, 2005).

\subsection{Psychosocial Development}

The positive benefits of social connections built through interactions with mentors appear to have broader psychosocial benefits that may carry over to multiple contexts. Deaf youths' opportunities to build cultural affiliations with the deaf community appear to be important contributors to psychosocial well-being (Gale et al., 2021; Hintermair 2008; Jambor \& Elliot, 2005). Deaf adults who are more strongly identified by the deaf community, as indicated by (a) percentage of friends who were deaf and (b) level of involvement with the deaf community, had higher self-esteem (Bat-Chava, 1994). The importance of connection to community, as well as potential deleterious effects of disconnection, is further illustrated by a study by Kent (2003), on self-identification of deaf and hard of hearing students in mainstreamed settings. 
Especially, in a survey of mainstreamed hard of hearing youth, Kent found that over half (56\%) did not identify as having a hearing disability. Those who did identify as having a hearing loss experienced significantly higher levels of loneliness compared to individuals who did not disclose or compared to their hearing peers. The potential negative effects of identity disclosure among deaf youth in mainstreamed settings spotlight ways in which role models can provide guidance or ameliorate some of the challenges of being known as or functioning as a deaf person in a hearing world.

Role models and mentors can be a part of how a deaf individual builds his or her own personal resources, resiliency, and strength (Hintermair, 2008). Deaf youth who worked with a deaf mentor or role model demonstrated an increased sense of worth (Rogers \& Young, 2011) and greater confidence than when they did not have a mentor (Foster \& MacLeod, 2004; Selwood, 2005).

Deaf youth who worked with deaf mentors also exhibited improvements in peer relationships and social interaction (Selwood, 2005). We can see that those psychosocial processes, including an increased sense of worth, self-confidence, acceptance of being deaf, and improved peer relationships, are all important components of developing resilience and psychosocial health. These benefits have great potential for making an impact on multiple dimensions of life beyond adolescence and the young adult years.

\section{Conclusion}

In sum, this literature review showed that role models for deaf individuals contribute to essential developmental processes across multiple life periods and settings, ranging from early childhood to the workplace. Understanding how role models prepare individuals to be thriving members of a strong social network requires a multidimensional approach. Especially, in the study carried out by Cawthon et al. (2016), five key developmental processes were identified as highly relevant to role-modeling and mentoring processes with deaf individuals: shifting parental attitudes, identity development, formation of navigational capital, language development, and psychosocial development. As opposed to a direct impact on tangible outcomes such as academic achievement or successful employment, role models appear to make a greater contribution to developmental processes such as the development of self-esteem, confidence, and identity, which become mediators for longer-term outcomes in academics and the workplace.

Furthermore, the literature review revealed also two key elements involved with effective role modeling for deaf individuals: high expectations and effective communication. These two elements cut across contexts, from home to school and to the workplace. The ways in which high expectations are expressed and affect communication is maintained by role models for deaf individuals in professional environments may mirror what is seen in analyses of effective mentoring of minority youth (Allen et al., 2004; Cawthon et al., 2016). For example, formal programs to recruit, train, and retain professionals from underrepresented backgrounds also emphasize psychosocial supports within mentor dyads (Yager, Waitzkin, Parker, \& Duran, 2007). Effective mentorship can also include honest discussion of difficult societal issues such as race, 
racism, and privilege (Chan, 2008), conversations that both require and build openness and trust within the dyad. This level of risk taking, and safety is essential to getting past the "surface" aspects of an experience and understanding greater societal norms and challenges that individual might face. What is critical is that the role model be able to instill those high expectations and maximize opportunities, while at the same time building the foundation that will allow that individual to be successful in the future.

The final theme that emerged as a necessary component to consider when discussing role models for deaf individuals was that of the multidimensional cultural affiliations of role models. Although hearing individuals can provide high levels of support, and even advocate on behalf of deaf individuals as institutional agents, the present synthesis indicates that their function is complemented by the unique contributions of role models who are deaf themselves. However, a significant gap in the literature exists in terms of multidimensional cultural affiliations and shared identities beyond and intersecting with deafness, such as race, ethnicity, gender, additional disability, and sexual identity.

Hence, the opportunity to have role models who share similar cultural affiliations is crucial for students who are members of underrepresented groups (Barnett, Gibson, \& Black, 2003; Cawthon et al., 2016; Ensher \& Murphy, 1997). These affiliations are also important characteristics to consider in role models for deaf individuals. Future work in this area will need to expand concepts of role models for deaf individuals to include multiple identities, including but not limited to deaf identity.

Finally, this discussion about role models and deaf individuals will help families and professionals acquire a deeper and more nuanced understanding of the importance and function of role models for deaf individuals, particularly as they move towards adulthood. When hearing parents of a child with a newly identified hearing loss looks ahead, they may only be able to focus on what is missing. The deaf role model has an opportunity to present to the family a perspective of optimism. By sharing stories, experiences and asking questions, the family may be able to take a step beyond that first awkward moment of how to talk to a deaf or hard of hearing person. The deaf adult can also model effective and meaningful communication and build a relationship with the family and support the relationship between the parent and child.

Therefore, realistic expectations for the deaf, positive reactions to deafness, and exposure to deaf role models will better develop a bicultural identity and form healthy relationships with deaf and hearing people alike. Hearing adults living or working with deaf people of all ages will benefit from contact with deaf adults in terms of understanding and accepting deafness and deaf culture.

\section{Conflict of Interest Statement}

The authors declare no conflicts of interests. 


\section{About the Authors}

Stergiani Giaouri is an Assistant Professor of School Psychology at the University of Western Macedonia, Greece. She has graduated from the Department of Psychology, Aristotle University of Thessaloniki. She also did postgraduate studies in Social Psychiatry and Child Psychiatry at the School of Medicine in the University of Ioannina. At the University of Western Macedonia pursued doctoral study leading to doctorate in Special Education. She works as a research assistant in various projects of the University and as a teaching assistant in special education and school psychology courses. She has published research papers in refereed academic journals and books.

ResearchGate: www.researchgate.net/profile/Stergiani Giaouri

Email: sgiaouri@uowm.gr

Spyridoula Karipi is the Head of the Kindergarten (preschool) for the Deaf of Argyroupolis since 2008. She holds a master's degree in Special Education (specialized in Deafness) and she is a $\mathrm{PhD}$ candidate at the University of Western Macedonia. Spyridoula is proficient in Greek Sign Language. She has published special teaching material for developing readiness and learning skills in Greek Sign Language for children of preschool and $1^{\text {st }}, 2^{\text {nd }}$ and $3^{\text {rd }}$ grades. Spyridoula's research interests include teaching Sign Language as a first language as well as teaching first literacy skills in Deaf and hard of hearing children.

E-mail: skaripi78@gmail.com

Anastasia Alevriadou is a Full Professor of Psychology (emphasis is Special Education), at the Aristotle University of Thessaloniki, Greece. She holds her undergraduate and postgraduate degrees in Psychology at the Aristotle University of Thessaloniki, Greece. Her research interests include special education, neurodevelopmental disorders and transition of people with disabilities at the job market. She has published more than 150 research papers in refereed academic journals and 5 books. She is a Fulbright Scholar in 2019 at the Ohio State University, Nisonger Center.

ResearchGate: www.researchgate.net/profile/Anastasia Alevriadou

Email: alevriadou@psy.auth.gr

Marianna Hatzopoulou is a teacher for the Deaf and hard of hearing children and a Greek Sign Language interpreter. She received her PhD on Greek Sign Language Acquisition from Department of Linguistics, Stockholm University, Sweden. Today is the Head of the $2^{\text {nd }}$ Local Assessment and Support Centre, for children with special needs, $2^{\text {nd }}$ K.E.S.Y. B' Athens. She has published accessible educational materials and teaching materials for Greek Sign Language and worked on curriculum development for Deaf/hard of hearing children on written Greek, preschool and elementary education. Her research interests include Sign Language Acquisition, Deaf/hard of hearing children literacy development, assessment and family support.

E-mail: mhatzopoulou@gmail.com

Vassilis Kourbetis holds a Masters in the Education of the Deaf and a Doctorate in Applied Psycholinguistics and Deafness from Boston University. Vassilis is a senior Counselor of the Hellenic Ministry of Education and a professor at Hellenic Open University He has created educational tools for the education and communication for the 
Deaf and the hearing with the use of Greek Sign Language. His main research interests span the areas of Deaf education, the Deaf Community and the structure and use of Greek Sign Language. Vassilis is proficient in Greek Sign Language and American Sign Language.

E-mail: kourbetis1@gmail.com, vkourmpetis@minedu.gov.gr

\section{References}

Ahlgren, I., \& Hyltenstam, K. (1994). Bilingualism in Deaf education. Hamburg: Signum. Allen, T., Eby, L., Poteet, M., Lentz, E., \& Lima, L. (2004). Career benefits associated with mentoring protégés: A meta-analysis. Journal of Applied Psychology, 89, 127-136.

Barnett, E., Gibson, M., \& Black, P. (2003). Proactive steps to successfully recruit, retain, and mentor minority educators: Issues in education. Journal of Early Education and Family Review, 10(3), 18-28.

Bat-Chava Y. (2000). Diversity of Deaf identities. American Annals of the Deaf, 145(5), 420428.

Baumeister, R. (1997). The self and society: Changes, problems, and opportunities. In R. Ashmore \& L. Jussim (Eds.), Self and identity (pp. 191-217). New York: Oxford University Press.

Benedict, B., \& Sass-Lehrer, M. (2007). Deaf and hearing partnerships: Ethical and communication considerations. American annals of the Deaf 152(3), 275-282.

Bone, J., \& Slate, J. (2011). Student ethnicity, teacher ethnicity, and student achievement: On the need for a more diverse teacher workforce. Journal of Multiculturalism in Education, 7, 1-22.

Byatt, T. J., Dally, K., \& Duncan, J. (2019). Systematic review of literature: Social capital and adolescents who are Deaf or hard of hearing. Journal of Deaf Studies and Deaf Education, 24(4), 319-332.

Cawthon, S., Johnson, P., Garberoglio, C., Schoffstall, S. (2016). Role models as facilitators of social capital for Deaf Individuals: A research synthesis. American Annals of the Deaf, 161 (2), 115-127.

Chandler, D., \& Roberts-Young, D. (1998). The construction of identity in the personal home pages of adolescents. Retrieved from University of Wales, Aberystwyth, http://visual-memory.co.uk/daniel/Documents/short/strasbourg.html.

Covell, J. (2006). The learning styles of Deaf and non-Deaf preservice teachers in Deaf education (Doctoral dissertation). Available from ProQuest Dissertations and Theses database. (UMI No. 3260507).

Da Costa, J., Klak, R., \& Schinke, R. (2000). Mentoring: Promoting inner-city elementary school student literacy. Paper presented at the annual meeting of the American Educational Research Association, New Orleans, LA. (ERIC Document Reproduction Service No. ED 439439).

Davies, S. (1991). The transition toward bilingual education of Deaf children in Sweden and Denmark: Perspectives on language. Sign Language Studies, 71, 169-95. 
De Clerck, G. A. M. (2007). Meeting global Deaf peers, visiting ideal Deaf places: Deaf ways of education leading to empowerment, an exploratory case study. American Annals of the Deaf, 152(1), 5-19.

De Clerck, G. A. M., \& Golos, D. (2019). Minimizing the impact of language deprivation and limited access to role models on Deaf identity development in children and young adults: Global perspectives for positive change. In I. W. Leigh \& C. A. O'Brien (Eds.), Deaf Identities (pp. 193-225). New York: Oxford University Press.

Delk, L., \& Weidekamp, L. (2001). Shared reading project: Evaluating implementation processes and family outcomes. Washington, DC: Laurent Clerc National Deaf Education Centre, Gallaudet University.

Drasgow, E. (1993). Bilingual/bicultural Deaf education: An overview. Sign Language Studies, 80, 243-66.

Eby, L., Allen, T., Evans, S., Ng, T., \& Dubois, D. (2008). Does mentoring matter? A multidisciplinary meta-analysis comparing mentored and non-mentored individuals. Journal of Vocational Behavior, 72(2), 254-267.

Ensher, E., \& Murphy, S. (1997). Effects of race, gender, perceived similarity, and contact on mentor relationships. Journal of Vocational Behavior, 50(3), 460-481.

Foster, S., \& MacLeod, J. (2004). The role of mentoring relationships in the career development of successful Deaf persons. Journal of Deaf Studies and Deaf Education, 13(9), 442-458.

Gale, E., Berke, M., Benedict, B., Olson, S., Putz, K., \& Yoshinaga-Itano, C. (2021). Deaf adults in early intervention programs. Deafness $\mathcal{E}$ Education International, 23(1), 324.

Gallegos, R., \& Lawrence, C. (2010). Early intervention and school age outreach services provided by a school for the Deaf-National survey, CEASD Conference.

Golos, D., Moses, A., Roemen, B., Cregan, G. (2018). Cultural and Linguistic Role Models: A Survey of Early Childhood Educators of the Deaf. Sign Language Studies, 19 (1), 40-74.

Gravel, J., \& Galatioto, J. (2003). Communication Options for Children with Hearing Loss. Mental Retardation and Developmental Disabilities Research Reviews 9(4), 243-251.

Hadadian, A., \& Rose, S. (1991). An investigation of parents' attitudes and the communication skills of their Deaf children. American Annals of the Deaf, 136(3), 273-277.

Hadjikakou, K., \& Nikolaraizi, M. (2008). The communication experiences of adult Deaf people within their family during childhood in Cyprus. Deafness \& Education International, 10 (2), 60-79.

Hatzopoulou, M. (2008). Acquisition of Reference to Self and Others in Greek Sign Language. From Pointing Gesture to Pronominal Pointing Signs. Doctoral Dissertation. Stockholm: Stockholm University.

Haualand, H., Grønningsæter, A., \& Hansen, ILS. (2003). Uniting divided worlds: Identity, family and education in the life, projects of Deaf and hard of hearing people. Disability Studies Quarterly, 23 (2), 75-88. 
Haualand, H., \& Holmström, I. (2019). When language recognition and language shaming go hand in hand-Sign Language ideologies in Sweden and Norway. Deafness E Education International, 21(2-3), 99-115.

Hauser, P. (2015). Effects of Linguisticism and Audism on the Developing Deaf Person [video]. https://www.youtube.com/watch?v=73zUW760Oxg.

Haycock, K. (2001). Closing the achievement gap. Educational Leadership, 58(6), 6-11.

Henderson, R., Johnson, A., \& Moodie, S. (2014). Parent-to-parent support for parents with children who are Deaf or hard of hearing: A conceptual framework. American Journal of Audiology, 23, 437-448.

Hindley, P. (2005). Mental health problems in Deaf children. Current Paediatrics, 15, 114119.

Hintermair, M. (2000). Hearing impairment, social network, and coping: The need for families with hearing impaired children to relate to other parents and to hearingimpaired adults. American Annals of the Deaf, 145(1), 41-53.

Hintermair, M. (2007). Prevalence of socioemotional problems in Deaf and hard of hearing children in Germany. American Annals of the Deaf, 152(3), 320-330.

Hintermair, M. (2008). Self-esteem and satisfaction with life of Deaf and hard-of-Hearing people- a resource-oriented approach to identity work. Journal of Deaf Studies and Deaf Education, 13(2), 278-300.

Hoffmeister, R., \& Caldwell-Harris, C. (2014). Acquiring English as a second language via print: The task for deaf children. Cognition, 132, 229-242.

Holcomb, T. (1997). Development of Deaf bicultural identity. American Annals of the Deaf, 142(2), 89-93.

Holcomb, T. (2013). Introduction to American Deaf culture. New York, NY: Oxford University Press.

Hulsebosch, P., \& Myers, L. (2002). Minority parents as cultural mediators for education: Deaf parents mentoring hearing parents of Deaf children. The School Community Journal, 12(1), 73-89.

Humphries, T., Kushalnagar, P., Mathur, G., Napoli, D. J., Padden, C., Rathmann, C., \& Smith, S. (2017). Discourses of prejudice in the professions: The case of sign languages. Journal of Medical Ethics: Journal of the Institute of Medical Ethics, 43(9), $648-652$.

Jackson, C. (2011). Family supports and resources for parents of children who are Deaf or hard of hearing. American Annals of the Deaf, 156(4), 343-362.

Jackson, C., \& Turnbull, A. (2004). Impact of Deafness on Family Life: A Review of the Literature. TECSE 24(1)15-29.

Jambor, E., \& Elliott, M. (2005). Self-esteem and coping strategies among Deaf students. Journal of Deaf Studies and Deaf Education, 10(1), 63-81.

Kecman, E. (2018). Old challenges, changing contexts: reviewing and reflecting on information provision for parents of children who are Deaf or hard-of-hearing. Deafness $\mathcal{E}$ Education International, 22(1), 3-24.

Kent, B. (2003). Identity issues for hard-of-hearing adolescents aged 11, 13, and 15 in mainstream setting. Journal of Deaf Studies and Deaf Education, 8(3), 315-324. 
Kourbetis, V., Adamopoulou, A., \& Ferentinos, S. (2005). Assessment of Deaf Education from Deaf Communities of Europe: An Inter-state Comparative Study. Education and Science, I(2), 169-196.

Kram, K. (1985). Mentoring at work: Developmental relationships in organizational life. Glenview, IL: Scott Foresman.

Leeson, L. (2006). Signed languages in education in Europe - a Preliminary exploration. Preliminary study. Strasbourg: Language Policy Unit, Council of Europe [consulted November 2010]. Available at: www.coe.int/lang

Leigh, I. (2009). Reflections on Identity. Presented at the EHDI Conference. Dallas, TX. http://www.infanthearing.org/meeting/ehdi2009/EHDI\%202009\%20Presentations 39.pdf

Luckner, J., \& Velaski, A. (2004). Healthy families of children who are Deaf. American Annals of the Deaf, 149(4), 324-335.

Mahshie, S. (1995). Educating Deaf children bilingually. Washington, DC: Gallaudet University Press.

Marschark, M., Siple, P., Lillo-Martin, D., Campbell, R., \& Everhart, V. (1997). Counterpoints: Cognition, memory, and language. Relations of language and thought: The view from Sign Language and Deaf children. Oxford University Press.

Maxwell-McCaw, D. (2001). Acculturation and psychological well-being in Deaf and hard-of-hearing people. Doctoral dissertation, George Washington University. Dissertation Abstracts International, 61 (11-B), 6141.

McKee, R., \& Connew, B. (2001). People of the eye: Stories from the Deaf world. Wellington, New Zealand: Bridget Williams Books.

McKee, D., \& Rosen, R. (2014). Teaching and learning signed languages: International perspectives and practices. Springer.

Meier, K., \& Stewart, J. (1992). The impact of representative bureaucracies: Educational systems and public policies. American Review of Public Administration, 22(3), 157171.

Michell, R., \& Karchmer, M. (2004). Chasing the mythical ten percent: Parental hearing status of Deaf and hard of hearing students in the United States. Sign Languages Studies, 4(2), 138-63.

Moeller, M., Carr, G., Seaver, L., Stredler-Brown, A., \& Holzinger, D. (2013). Best practices in family- centered early intervention for children who are Deaf or hard of hearing: An international consensus statement. Journal of Deaf Studies and Deaf Education, 18(4), 429-445.

Mohay, H., Milton, L., Hindmarsh, G., \& Ganley, K. (1998). Deaf models as communication models for hearing families with Deaf children. In A. Weisel (Ed.), Issues Unresolved: New Perspectives on Language and Deaf Education (pp. 76-87). Washington, DC: Gallaudet University Press.

Moores, D. (1996). Educating the Deaf. Boston, MA: Houghton Mifflin Co.

Moores, D. (2001). Educating the Deaf: Psychology, principles, and practices (5th ed.). Boston: Houghton Mifflin. 
Moses, A., Golos, D., \& Holcomb, L. (2018). Perspectives on practice: Creating and using educational media with a cultural perspective of Deaf people. Language Arts, 96 (1), $67-71$.

Napier, J., Leigh, G., \& Nann, S. (2007). Teaching Sign Language to Hearing Parents of Deaf Children: An Action Research Process. Deafness and Education International, 9(2), 83-100.

Nikolaraizi, M., \& Hadjikakou, K. (2006). The role of educational experiences in the development of Deaf identity. Journal of Deaf Studies and Deaf Education, 11(4), 477492.

Ogden, P. (1997). The silent garden: Raising your Deaf child. Washington, DC: Gallaudet University Press.

Parasnis, I. (1996). Cultural and Language Diversity and the Deaf Experience. Cambridge, NY: Cambridge University Press.

Parasnis, L., Samar, V., \& Fischer, S. (2005). Deaf college students' attitude toward racial/ethnic diversity, campus climate, and role models. American Annals of the Deaf, 150(1), 47-58.

Petersen, A., Kinoglu, S., Gozali-Lee, E., \& Martin Rogers, N. (2016). Lifetrack's Deafmentor family program: An evaluation of the experiences and outcomes for participating families. Retrieved from https://www.wilder.org/sites/default/files/imports/LifetrackDea fMentorProgram 8-16.pdf.

Rhodes, J. (2005). A model of youth mentoring. In D. DuBois \& M. Karcher (Eds.), Handbook of youth mentoring (pp. 30-43). Thousand Oaks, CA: Sage.

Rogers, K., \& Young, A. (2011). Being a Deaf Role Model: Deaf People's Experiences of Working with Families and Deaf Young People. Deafness E Education International, $13(1), 2-16$.

Sass-Lehrer, M. (2016). Early intervention for Deaf and hard-of-hearing infants, toddlers, and their families: Interdisciplinary perspectives. Oxford University Press.

Schein, J., \& Delk, M. (1974). The Deaf population of the United States. Silver Springs, MD: National Association of the Deaf.

Schimmel, R., \& Monaghan, C. (1983). Deaf awareness through literature using Deaf adults as role models. American Annals of the Deaf, 128 (7), 890-93.

Scott, J. A., \& Henner, J. (2020). Second verse, same as the first: On the use of signing systems in modern interventions for Deaf and hard of hearing children in the USA. Deafness E Education International, 23(2), 123-141.

Selwood, J. (2005). Perspectives on a Deaf mentoring programme: Does it make a difference? Master's thesis, University of Canterbury, Christchurch, New Zealand. Retrieved from University of Canterbury website: http://hdl.handle.net/10092/2867.

Siegel, I. (2000). The educational and communication needs of Deaf and hard of hearing children: A statement of principle on fundamental educational change. American Annals of the Deaf, 145 (2), 64-77.

Sinclair, M., Christenson, S., \& Thurlow, M. (2005). Promoting school completion of urban secondary youth with emotional or behavioral disabilities. Exceptional Children, 71(4), 465-482. 
Spencer, P., \& Gutfreund, M. (1990). Directiveness in mother-infant interactions. In D. Moores, \& K. Meadows-Orlans (Eds.), Educational and developmental aspects of Deafness (pp 350- 365). Washington, DC: Gallaudet University Press.

Storbeck, C., \& Young, A. (2015). Early intervention in challenging national contexts. In M. Sass- Lehrer (Ed.), Early intervention for Deaf and hard-of-hearing infants, toddlers, and their families: Interdisciplinary perspectives (pp. 305-328). New York, NY: Oxford University Press.

Sutherland, H., Griggs, M., \&Young, A. (2003). Deaf adults and family intervention projects. In C. Gallaway \& A. Young (Eds.), Deafness and Education in the UK: Research Perspectives (pp. 5-20). London, England: Whurr Publishers.

Svartholm, K. (1993). Bilingual education for the Deaf in Sweden. Sign Language Studies, 81, 291-332.

Takala, M., Kuusela, J., \& Takala, E. (2001). A good future for Deaf children: A five-year Sign Language intervention project. American Annals of the Deaf, 145(4), 366-74.

Thompson, L., \& Kelly-Vance, L. (2001). The impact of mentoring on academic achievement of at-risk youth. Children and Youth Services Review, 23(3), 227-242.

Tyler, N., Yzquierdo, Z., Lopez-Reyna, N., \& Flippin, S. (2004). Cultural and linguistic diversity and the special education workforce: A critical overview. The Journal of Special Education 38(1), 22-38.

Wald, R., \& Knutson, J. (2000). Deaf cultural identity of adolescents with and without cochlear implants. Annals of Otology, Rhinology, and Laryngology, 12(2), 87-89.

Watkins, S., Pittman, P., \& Walden, B. (1998). The Deaf mentor experimental project for young children who are Deaf and their families. American Annals of the Deaf, 143(1), 29-34.

Wilkens, G., \& Hehir, T. (2008). Deaf education and bridging social capital: A theoretical approach. American Annals of the Deaf, 153(3), 275-84.

Woodward J. (1972). Implications for sociolinguistic research among the deaf. Sign Language Studies 1, 1-7.

World Health Organization. (2018). Deafness and hearing loss. Retrieved from https://www.who.int/news-room/fact-sheets/detail/Deafness-and-hearing-loss.

Yager, J., Waitzkin, H., Parker, T., \& Duran, B. (2007). Educating, training, and mentoring minority faculty and other trainees in mental health services research. Academic Psychiatry 31(2), 146-151.

Yoshinaga-Itano, C. (2014). Principles and guidelines for early intervention after confirmation that a child is Deaf or hard of hearing. The Journal of Deaf Studies and Deaf Education, 19 (2), 143-175.

Young, A. (2003). Parenting and Deaf children: A psycho-social literature-based framework. London: NDCS.

Young, A., Griggs, M., \& Sutherland, H. (2000). Deaf child and family intervention services using Deaf adult role models: A national survey of development, practice and progress. London: RNID. 
Zand, D., Thomson, N., Cervantes, R., Espiritu, R., Klagholz, D., LaBlanc, L., \& Taylor, A. (2009). The mentor-youth alliance: The role of mentoring relationships in promoting youth competence. Journal of Adolescence, 32(1), 1-17. 
Creative Commons licensing terms

Authors will retain the copyright of their published articles agreeing that a Creative Commons Attribution 4.0 International License (CC BY 4.0) terms will be applied to their work. Under the terms of this license, no permission is required from the author(s) or publisher for members of the community to copy, distribute, transmit or adapt the article content, providing a proper, prominent and unambiguous attribution to the authors in a manner that makes clear that the materials are being reused under permission of a Creative Commons License. Views, opinions and conclusions expressed in this research article are views, opinions and conclusions of the author(s). Open Access Publishing Group and European Journal of Special Education Research shall not be responsible or answerable for any loss, damage or liability caused in relation to/arising out of conflict of interests, copyright violations and inappropriate or inaccurate use of any kind content related or integrated on the research work. All the published works are meeting the Open Access Publishing requirements and can be freely accessed, shared, modified, distributed and used in educational, commercial and non-commercial purposes under a Creative Commons Attribution 4.0 International License (CC BY 4.0). 